\title{
Número de operações mecanizadas na colheita do café
}

\author{
Number of mechanical operations in the coffee harvest
}

\author{
Felipe Santinato ${ }^{\mathrm{I}}$ Renato Adriane Alves Ruas ${ }^{\text {II }}$ Rouverson Pereira da Silva ${ }^{\text {III }}$ \\ Alberto Carvalho Filho ${ }^{\text {II }}$ Roberto Santinato ${ }^{\text {IV }}$
}

\section{RESUMO}

A realização de mais de uma operação da colhedora de café pode aumentar a eficiência de colheita dos frutos, minimizando a quantidade de café remanescente nas plantas e a necessidade de repasse manual. O repasse manual comumente encarece o processo de produção e promove maiores danos às plantas em relação à colheita mecanizada. Entretanto, deve-se conhecer qual número de operações da colhedora é necessário para derriçar completamente os frutos dos cafeeiros, em lavouras que apresentem diferentes cargas produtivas, notadamente as de cargas mais elevadas, por apresentarem maior dificuldade em serem totalmente colhidas. Portanto, objetivou-se, com este trabalho, avaliar o número de operações da colhedora, em duas lavouras de café, para uma colheita eficiente. Foram comparadas duas situações: lavoura com carga intermediária (50,78 sacas de café ben ha $\mathrm{h}^{-1}$ ) e lavoura com carga alta (121,54 sacas de café ben $\mathrm{ha}^{-1}$ ), na região do Cerrado Mineiro, utilizando de uma a seis operações de uma colhedora KTR. Utilizou-se delineamento de blocos ao acaso e quatro repetições. Avaliou-se a quantidade de café caido, remanescente, colhido e eficiência de colheita. Obtevese que, para que a quantidade de café remanescente nas plantas seja suficiente para dispensar o repasse manual, são necessárias três operações da colhedora de café em cargas elevadas e duas em cargas intermediárias. Independentemente da carga de café, utilizar três ou mais operações da colhedora colhe maior quantidade de frutos, no entanto, sem diferir quanto à eficiência de colheita da colheita com duas operações.

Palavras-chave: cafeicultura, eficiência de colheita, mecanização.

\section{ABSTRACT}

Performing more than one operation of coffee harvester can increase fruit harvest efficiency by minimizing the amount of remaining plants and the need for manual transfer. This manual harvest makes often more expensive the production process and promote more damage to the plants in relation to mechanization. However, it should know how many operations it is necessary to completely harvest the fruits of the trees, in fields that have different production loads, especially the higher loads, since they are more difficult to be fully harvested. Therefore, the aim of this study was to assess the number of harvester operations in two coffee plantations, for an efficient harvesting. Two situations were compared: crop with intermediate load (50.78 benefited coffee bags $\mathrm{ha}^{-1}$ ) and tillage with high load (121.54 benefited coffee bags $\mathrm{ha}^{-1}$ ) on the Cerrado Mineiro region, using one to six operations of a KTR harvester. It was used a randomized block design with four replications. The number of fallen coffee, remainned harvested and harvesting efficiency were evaluated. It was found that for the remainned amount of coffee plants, to dispense the manual harvest it is required three operations of coffee harvester at high loads and two at intermediate loads. Regardless of the coffee load, using three or more harvester operations, a larger amount of fruits was harvested, without differing in crop harvest efficiency with two operations.

Key words: coffee growing, harvesting efficiency, mechanization.

\section{INTRODUÇÃO}

Tendo em vista a maior disponibilidade na locação de colhedoras e, principalmente, o crescente aumento do custo e escassez de mão-de-obra para realização da colheita manual, a mecanização tem se tornado uma boa opção de colheita para os cafeicultores brasileiros. Diversos estudos serviram para elevar a eficiência de colheita, como o aperfeiçoamento das

\footnotetext{
IPrograma de Pós-graduação em Agronomia, Produção Vegetal, Faculdade de Ciências Agrárias e Veterinárias (FCAV), Universidade Estadual Paulista (UNESP), Via de Acesso Prof Paulo Donato Castellane, s/n, 14884-900, Jaboticabal, SP, Brasil. E-mail: fpsantinato@hotmail.com. Autor para correspondência.

IIniversidade Federal de Viçosa (UFV), Rio Paranaíba, MG, Brasil.

IIIDepartamento de Engenharia Rural, FCAV, UNESP, Jaboticabal, SP, Brasil.

IV Santinato \& Santinato Cafés Ltda, Rio Paranaíba, MG, Brasil.
} 
regulagens de velocidade operacional e vibração das hastes (OLIVEIRA et al., 2007a; CASSIA et al., 2013). No entanto, normalmente, há a necessidade de realizar o repasse manual, pois dependendo da carga, a colhedora dificilmente consegue derriçar todos os frutos das plantas com apenas uma operação. Isso ocorre devido ao fato de os frutos apresentarem estádio de maturação desuniforme, demandando assim, uma força de desprendimento diferente entre eles (SILVA et al., 2010).

Quanto maior a carga de café, maior será a exigência de "energia" da máquina para derriçar os frutos (SANTINATO et al., 2014), por isso que, dependendo da carga pendente, deve-se ajustar a colhedora quanto a vibração das hastes e a velocidade operacional. No entanto, deve-se limitar essa energia, pois, vibrações das hastes muito elevadas e velocidades operacionais reduzidas podem promover severos danos às plantas (OLIVEIRA et al., 2007). Tal fato sugere utilizar mais de uma operação ("passada") da colhedora, regulando-a para aplicar uma menor quantidade de energia em cada uma das operações.

A realização de mais de uma operação da colhedora de café pode aumentar a eficiência de colheita dos frutos, minimizando a quantidade de café remanescente nas plantas e a necessidade de repasse manual. O repasse manual comumente encarece o processo de produção (LANNA \& REIS, 2012) e promove maiores danos às plantas em relação à colheita mecanizada (OLIVEIRA et al., 2007b).

Outro ponto positivo do emprego da colhedora em repetidas operações é que a colheita pode ser realizada em momentos diferentes, o que possibilita à máquina colher maior porcentagem de frutos no estádio de maturação cereja, agregando valor à produção. Isso ocorre, pois dentro do intervalo entre uma operação e outra, os frutos no estádio verde amadurecem para o estádio cereja, ficando disponíveis em maior quantidade para serem colhidos. Aliada a essa prática, pode-se ainda utilizar técnicas de remoção de varetas e ajustes de velocidade operacional e vibração diferentes em cada uma das operações, sendo esta prática denominada colheita seletiva do café (SILVA et al., 2013).

Entretanto, deve-se conhecer qual o número de operações da colhedora são necessárias para derriçar completamente os frutos dos cafeeiros, em lavouras que apresentem diferentes cargas produtivas, notadamente as de carga mais elevada que apresentam maior dificuldade de colheita. Portanto, objetivou-se, com este trabalho, avaliar a colheita mecanizada em lavouras de café, empregando-se repetidas operações da colhedora.

\section{MATERIAL E MÉTODOS}

O trabalho foi realizado nas Fazendas São João Grande e Dona Neném, no município de Patos de Minas, MG, localizadas nas coordenadas

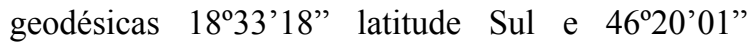
longitude Oeste, na região do Cerrado mineiro, com altitude média de $1100 \mathrm{~m}$ e clima Cwa, de acordo com a classificação de KÖEPPEN (1948). A lavoura da Fazenda São João Grande possui plantio comercial de cafeeiros irrigados sob pivô central. A área possui aproximadamente 54,0ha, com declividade média de $3,8 \%$. A cultivar transplantada na área foi a 'Catuaí Vermelho IAC 144', no ano de 2003, no espaçamento de 4,0 metros entre linhas e $0,5 \mathrm{~m}$ entre plantas, com densidade populacional de 5.000 plantas ha-1.

Na Fazenda Dona Neném, a lavoura de café é irrigada por gotejamento e plantada em renque mecanizado. Possui aproximadamente 30,0ha e o talhão apresenta em média $2 \%$ de declividade, onde foram transplantados, em 2007, com espaçamento de 4,0m entre linhas e $0,5 \mathrm{~m}$ entre plantas (5.000 plantas ha $^{-1}$ ), da cultivar 'Catuaí Vermelho IAC 144'. As colheitas foram realizadas entre os dias 12/6/2013 e 12/8/2013.

Foram comparadas duas situações: lavoura com carga intermediária (Fazenda São João Grande) e lavoura com carga alta (Fazenda Dona Neném) com 50,78 e 121,54 sacas de café ben. ha $^{-1}$, respectivamente. Vale ressaltar que ambas as produtividades são consideradas elevadas no Brasil (FERNANDES et al., 2012; CONAB, 2014). As lavouras apresentavam na lavoura de carga intermediária 26,4, 47,2, 26,4\% de frutos nos estádios verde, maduro e seco, respectivamente. E na lavoura de carga alta os frutos estavam com 30,2, 54,5 e $15,1 \%$ de verde, maduro e seco.

A colheita mecanizada nas duas fazendas foi realizada utilizando colhedora tracionada da marca Jacto, modelo KTR, fabricada em 2003, tendo aproximadamente 5.800 horas trabalhadas. Em todas as operações, utilizou-se vibração das hastes de 850rpm (1.020 ciclos minuto $\left.^{-1}\right)$ e velocidade operacional de $1,05 \mathrm{~km} \mathrm{~h}^{-1}$. A colhedora foi tracionada por trator da marca New Holland, modelo TT 3880F, $4 \times 2$ TDA, com potência nominal de $65 \mathrm{cv}$ a $2.200 \mathrm{rpm}$, cujo acionamento se dá por meio da TDP, a 540rpm, operando sempre no mesmo sentido de deslocamento. O café colhido foi depositado em uma carreta modelo Cargo 5.000, dotada de dois eixos, com capacidade de armazenamento de $5,18 \mathrm{~m}^{3}$, tracionada por um trator idêntico ao que tracionou a colhedora.

O experimento consistiu de seis tratamentos, cada um deles correspondente a um 
número de operações da colhedora, ou seja: $\mathrm{T} 1=$ uma operação, T2 = duas operações, T3 = três operações, $\mathrm{T} 4=$ quatro operações, T5 = cinco operações, T6 = seis operações. Os tratamentos foram delineados em blocos casualizados, e executados com intervalo de doze dias entre eles. Realizaram-se quatro repetições, totalizando 24 parcelas, em cada uma das fazendas.

Para cada tratamento, foram avaliadas dez plantas em cada parcela em duas linhas de cafeeiros, uma ao lado da outra. Em uma das linhas, foi realizada a determinação de produtividade. $\mathrm{Na}$ outra, passou-se a colhedora de café de acordo com o número de vezes correspondentes ao tratamento.

A determinação da produtividade da cultura, também denominada de carga inicial, foi estimada pela derriça manual de toda a carga pendente de cinco plantas, em cada uma das quatro repetições de cada tratamento, previamente à passagem da colhedora. Para isso, colocaram-se panos de "derriça" de aproximadamente $3,0 \mathrm{~m} \times 2,0 \mathrm{~m}$ sob a copa das cinco plantas, dos dois lados da linha de cafeeiro, de forma que um sobrepusesse o outro. Após isso, procedeu-se à derriça. $\mathrm{O}$ volume de café colhido foi quantificado individualmente através de recipiente graduado, para o cálculo da produtividade média $\left(\mathrm{L}_{\text {planta }}{ }^{-1}\right)$ e, em seguida, o volume foi convertido para sacas de café ben ha-1, conforme descrição de REIS et al. (2008). Para a caracterização do estádio de maturação dos frutos de café, em cada parcela, retirou-se uma amostra de 2,0L dos frutos, separandoos nos estádios verde, maduro (cereja mais passa) e seco e posteriormente quantificando-os.

Para a determinação da eficiência de colheita, foram colocados panos de derriça sob a copa de cinco plantas. Em seguida, operou-se a colhedora e, após sua operação, o café que se desprendera dos ramos e caíra nos panos foi coletado e teve seu volume determinado. Este café foi denominado Café perdido. Após a limpeza e abanação dos panos, eles foram novamente posicionados sob a copa das plantas e os frutos que ainda estavam nos ramos foram derriçados e também medidos, conforme descrito anteriormente. Este café foi denominado Café remanescente. De posse dos dados, determinou-se a quantidade de café colhido (Equação 01 e 02).

$$
\begin{aligned}
& \mathrm{CC}=\mathrm{C}_{\text {Ini }}-\mathrm{C}_{\text {Perdido }}-\mathrm{C}_{\text {Rem }} \\
& E f=\frac{C C}{C_{\text {Ini }}} .100
\end{aligned}
$$

Em que:

$C C=$ Café colhido (Sacas de café ben ha $^{-1}$ ); café ben $\mathrm{ha}^{-1}$ );

$C_{i n i}=$ Quantidade de café inicial (Sacas de

$$
C_{\text {Perdido }}=\text { Quantidade de café perdido }
$$

(Sacas de café ben ha-1);

$C_{\text {Rem }}=$ Quantidade de café remanescente (Sacas de café ben ha-1);

$E F=$ Eficiência de colheita $(\%)$.

Em cada uma das Fazendas, realizou-se a análise de variância para os dados de café caído, café remanescente, café colhido e eficiência de colheita e, quando procedente, empregou-se o teste de médias de Tukey a $5 \%$ de probabilidade. Também se realizou o teste t para a comparação dos dados, em porcentagem, entre as duas Fazendas. Em ambas as análises, utilizouse o programa estatístico SISVAR $^{\circledR}$ (FERREIRA, 2011).

\section{RESULTADOS E DISCUSSÃO}

$\mathrm{Na}$ lavoura de carga alta (121,54 sacas de café ben $\mathrm{ha}^{-1}$ ) houve diferença entre os tratamentos estudados para as variáveis quantidade de café caído, remanescente, colhido e eficiência de colheita $(\mathrm{P} \leq 0,05)$. A quantidade de café perdido, em decorrência da operação da colhedora, foi inferior quando se realizou apenas uma operação da colhedora (Tabela 1). Isso provavelmente ocorreu devido ao menor tempo de exposição das plantas com a máquina, pois, diminuindo o contato entre as hastes de derriça da colhedora e os ramos e frutos, reduz-se a possibilidade de os frutos se desprenderem dos ramos e caírem no chão após a operação da colhedora. Quanto maior o número de operações, maior a exposição das plantas às hastes da colhedora, pois, em todas as operações, utilizou-se a mesma velocidade operacional. As colheitas com duas ou mais operações da colhedora proporcionaram os mesmos valores de café perdido, ou seja, não houve aumento da queda de frutos no chão, já que $60 \%$ $(10,51$ sacas de café ben ha-1) caíram com a primeira operação e $40 \%\left(6,95\right.$ sacas de café ben ha $\left.^{-1}\right)$ na segunda. Por conta disso, os valores de café perdido se repetiram com duas a seis operações da colhedora. Em geral, a quantidade de café perdido no chão ficou entre 10 e $20 \%$, valor considerado aceitável nesse tipo de operação (OLIVEIRA et al., 2007; SANTINATO et al., 2014). Dessa forma, sugere-se que, caso adotado o sistema de recolhimento mecanizado do café do chão, pode ser realizado logo após a segunda operação da colhedora, não tendo que esperar o término da colheita, caso opte-se pela colheita com mais de duas operações.

A quantidade de café remanescente nas plantas foi superior na colheita com apenas uma operação, $34,83 \%$ da carga inicial, o que refletiu nas menores quantidades de café colhido e eficiência de colheita (Tabela 1). Este valor encontra-se abaixo do desempenho 
Tabela 1 - Quantidade de café caído, remanescente, colhido e eficiência de colheita em lavoura de café com carga alta, localizada na Fazenda Dona Neném no município de Patos de Minas, MG, safra 2013, em diferentes números de operações da colhedora.

\begin{tabular}{|c|c|c|c|c|}
\hline \multirow{2}{*}{ Número de operações da colhedora } & 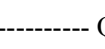 & de café (Sacas d & ha $\left.{ }^{-1}\right)$----------- & \multirow{2}{*}{ Eficiência de colheita $(\%)$} \\
\hline & Caído & Remanescente & Colhido & \\
\hline 1 & $10,51 \mathrm{a}$ & $42,01 \mathrm{c}$ & $69,12 \mathrm{c}$ & $56,64 \mathrm{c}$ \\
\hline 2 & $17,46 \mathrm{~b}$ & $6,38 \mathrm{~b}$ & $96,09 \mathrm{~b}$ & $78,98 \mathrm{~b}$ \\
\hline 3 & $17,46 \mathrm{~b}$ & $1,14 \mathrm{a}$ & $101,06 \mathrm{a}$ & $83,09 \mathrm{ab}$ \\
\hline 4 & $17,46 \mathrm{~b}$ & $0,53 \mathrm{a}$ & $102,80 \mathrm{a}$ & 84,67 a \\
\hline 5 & $17,46 \mathrm{~b}$ & $0,00 \mathrm{a}$ & $103,20 \mathrm{a}$ & $85,01 \mathrm{a}$ \\
\hline 6 & $17,46 \mathrm{~b}$ & $0,00 \mathrm{a}$ & $103,20 \mathrm{a}$ & $85,01 \mathrm{a}$ \\
\hline $\mathrm{CV}(\%)$ & 4,26 & 22,74 & 11,99 & 12,88 \\
\hline
\end{tabular}

*Médias seguidas de mesmas letras, comparadas nas colunas, não diferem entre si, pelo teste de Tukey a 5\% de probabilidade.

de colheita satisfatório, como relatado em trabalhos de CASSIA et al. (2013) e SILVA et al. (2013). Com duas operações, ocorreu redução de $85 \%$ na quantidade de café remanescente e elevação de $30 \%$ da eficiência de colheita em relação à colheita com uma operação.

As colheitas mecanizadas do café com três ou mais operações da colhedora foram suficientes para remover praticamente toda a carga inicial das plantas, dispensando a necessidade de repasse manual, fato não ocorrido na colheita com duas operações da colhedora que apresentou 6,38 sacas de café ben $h^{-1}$ remanescentes nas plantas. Apesar de apresentar eficiência operacional semelhante às colheitas com três ou mais operações da colhedora, a colheita com duas operações colheu 96,09 sacas de café ben ha ${ }^{-1}$ contra 101,06 sacas de café ben ha-1 da colheita com três operações.

$\mathrm{Na}$ lavoura de carga intermediária $(50,78$ sacas de café ben ha $\left.^{-1}\right)$, a análise de variância indicou que houve diferença entre os tratamentos apenas para as variáveis quantidade de café remanescente, colhido e eficiência de colheita. A quantidade de café perdido foi a mesma em todos os tratamentos, cerca de $10 \%$ da carga inicial. Dessa forma, as colheitas com repetidas operações da colhedora não elevaram a quantidade de café perdido (Tabela 2).

Isso ocorreu por que a quantidade de café presente na planta, que foi passível de ser perdida para o solo em detrimento da operação da colheita, caiu no chão logo após a primeira operação da colhedora e a capacidade de recolhimento interno da colhedora foi suficiente para impedir que o restante dos frutos caísse no chão, sendo todos os cafeeiros derriçados colhidos. Tal fato sugere que, no caso de se adotar o sistema de recolhimento mecanizado (dispensando a varrição manual), o momento recomendado pode ser antecipado para logo após a primeira operação da colhedora, não exigindo que o produtor espere até o término da colheita, minimizando a perda de qualidade de bebida do café de chão, que se dá ao longo do tempo.

$\mathrm{Na}$ colheita com apenas uma operação da colhedora, a quantidade de café remanescente foi a maior: $22,72 \%$ da carga inicial, diminuindo conforme se aumentou o número de operações (Tabela 2). Também obteve a menor eficiência de colheita $(67,20 \%)$, colhendo 34,30 sacas de café ben $\mathrm{ha}^{-1}$. No caso dessa

Tabela 2 - Quantidade de café caído, remanescente, colhido e eficiência de colheita em lavoura de café com carga intermediária, localizada na Fazenda São João Grande no município de Patos de Minas, MG, safra 2013, em diferentes números de operações da colhedora.

\begin{tabular}{|c|c|c|c|c|}
\hline \multirow{2}{*}{ Número de operações da colhedora } & ----- Q & de café (Sacas de & $\left.\mathrm{ha}^{-1}\right)$------ & \multirow{2}{*}{ Eficiência de colheita (\%) } \\
\hline & Caído & Remanescente & Colhido & \\
\hline 1 & $5,12 \mathrm{a}$ & $11,39 \mathrm{c}$ & $34,30 \mathrm{c}$ & $67,20 \mathrm{c}$ \\
\hline 2 & $5,80 \mathrm{a}$ & $4,47 \mathrm{~b}$ & $40,12 \mathrm{~b}$ & $79,10 \mathrm{~b}$ \\
\hline 3 & $5,96 \mathrm{a}$ & $0,96 \mathrm{ab}$ & $43,44 \mathrm{a}$ & 85,70 a \\
\hline 4 & $5,96 \mathrm{a}$ & $0,00 \mathrm{a}$ & $43,97 \mathrm{a}$ & 86,80 a \\
\hline 5 & $5,96 \mathrm{a}$ & $0,00 \mathrm{a}$ & $43,97 \mathrm{a}$ & 86,80 a \\
\hline 6 & $5,96 \mathrm{a}$ & $0,00 \mathrm{a}$ & $43,97 \mathrm{a}$ & $86,80 \mathrm{a}$ \\
\hline $\mathrm{CV}(\%)$ & 3,06 & 37,15 & 10,74 & 11,89 \\
\hline
\end{tabular}

*Médias seguidas de mesmas letras, comparadas nas colunas, não diferem entre si pelo teste de Tukey a 5\% de probabilidade.

Ciência Rural, v.45, n.10, out, 2015. 
lavoura, foram necessárias somente duas operações da colhedora para derriçar completamente os frutos dos cafeeiros, já que a quantidade de café remanescente não diferiu estatisticamente de zero, obtendo eficiência de colheita de 79,10\%. Entretanto, a maior quantidade de café colhido foi obtida com três operações, colhendo 3,32 sacas de café ben $h^{-1}$ a mais que a colheita com duas operações (eficiência de 85,70\%).

Essa diferença de produção colhida sugere que a forma mais indicada de colher o café nesta lavoura também é utilizando três operações da colhedora. Além disso, a colheita com três operações pode aumentar a possibilidade de colher maior quantidade de café cereja, já que, durante o intervalo entre uma operação e outra, parte dos frutos verdes amadurecem, tornando-se cereja, notadamente quando se adota regulagens para a colheita seletiva do café (SILVA et al., 2013).

Através da análise realizada, comparando as duas lavouras, verificou-se diferença em todos os tratamentos estudados, pelo teste F, somente para a quantidade de café perdido. Houve diferença entre as duas lavouras no tratamento um para as variáveis quantidade de café remanescente e eficiência de colheita (Tabela 3). Para as demais comparações, não houve diferenças significativas. Notou-se que a colheita mecanizada do café utilizando várias operações da colhedora comportou-se de maneira diferenciada, devido à grande diferença entre as cargas iniciais das plantas (70,76 sacas de café ben $\left.\mathrm{ha}^{-1}\right)$.

A quantidade de café perdido na colheita com uma operação da colhedora foi maior na área de produtividade intermediária. Isso por que todo o café caído nesta lavoura ocorreu após a primeira operação. Além disso, nessa área, havia maior porcentagem de frutos no estádio de maturação seco ( $42 \%$ a mais), que se desprendem mais facilmente dos ramos e, por serem leves, caem para fora da colhedora, indo para o chão (SILVA et al., 2010). Nas colheitas com duas ou mais operações, os maiores valores foram obtidos na lavoura de carga alta, provavelmente, por que a carga elevada dificultou o sistema de recolhimento da colhedora, permitindo a queda dos frutos no chão.

A quantidade de café remanescente obtido na colheita com apenas uma operação da colhedora foi superior na lavoura de carga alta, refletindo em menores quantidades de café colhido e de eficiência de colheita. Quanto maior a carga de café nas plantas, maior é a exigência de energia para sua remoção (CASSIA et al., 2013). Em ambas as áreas, foram utilizadas as mesmas velocidades operacionais (mesmo tempo de exposição das plantas às hastes vibratórias) e vibração das hastes, de forma que a energia empregada na lavoura de carga alta não foi suficiente para se obter elevada eficiência de colheita, utilizando a colhedora apenas uma vez. Com duas operações, os valores de café remanescente e café colhido foram iguais nas duas áreas. Em ambas as áreas, os valores de eficiência de colheita corroboram com os encontrados por SILVA et al., (2003), na região do Sul de Minas Gerais, que obtiveram eficiência de colheita de $41,7 \%, 80,6 \%$ e $86,1 \%$, respectivamente, para as colheitas com uma, com duas e com três operações da colhedora.

\section{CONCLUSÃO}

A colheita mecanizada utilizando três ou mais operações não elevou a quantidade de café caído no chão. Isso já ocorreu a partir da segunda operação na lavoura de carga alta $(121,54$ sacas de café ben ha-1) e não se diferencia na lavoura de carga intermediária $\left(50,78\right.$ sacas de café ben $\left.\mathrm{ha}^{-1}\right)$.

Tabela 3 - Comparação entre lavoura de café com carga alta e intermediária com relação à porcentagem de café caído, remanescente e eficiência de colheita em função do número de operações da colhedora, em lavouras localizadas no município de Patos de MinasMG.

\begin{tabular}{|c|c|c|c|c|c|c|}
\hline \multirow[t]{2}{*}{ Número de operações da colhedora } & \multicolumn{2}{|c|}{-------------- Caído ------------- } & \multicolumn{2}{|c|}{------ Remanescente -------- } & \multicolumn{2}{|c|}{--- Eficiência de colheita (\%) --- } \\
\hline & $\mathrm{CA}^{*}$ & $\mathrm{CI}^{* *}$ & $\mathrm{CA}$ & $\mathrm{CI}$ & $\mathrm{CA}$ & $\mathrm{CI}$ \\
\hline 1 & 8,66 a & $10,04 \mathrm{~b}$ & $34,83 \mathrm{~b}$ & $22,72 \mathrm{a}$ & $56,64 \mathrm{~b}$ & $67,23 \mathrm{a}$ \\
\hline 2 & $14,41 \mathrm{~b}$ & $11,33 \mathrm{a}$ & $5,28 \mathrm{a}$ & 8,76 a & 78,98 a & $79,14 \mathrm{a}$ \\
\hline 3 & $14,41 \mathrm{~b}$ & $11,46 \mathrm{a}$ & 0,93 a & $1,88 \mathrm{a}$ & 83,09 a & 85,7 a \\
\hline 4 & $14,43 \mathrm{~b}$ & $11,64 \mathrm{a}$ & $0,44 \mathrm{a}$ & $0,0 \mathrm{a}$ & 84,67 a & $86,81 \mathrm{a}$ \\
\hline 5 & $14,43 \mathrm{~b}$ & $11,64 \mathrm{a}$ & $0,0 \mathrm{a}$ & $0,0 \mathrm{a}$ & 85,01 a & 86,81 a \\
\hline 6 & $14,43 \mathrm{~b}$ & $11,64 \mathrm{a}$ & $0,0 \mathrm{a}$ & $0,0 \mathrm{a}$ & 85,01 a & $86,81 \mathrm{a}$ \\
\hline $\mathrm{CV}(\%)$ & \multicolumn{2}{|c|}{7,24} & \multicolumn{2}{|c|}{39,55} & \multicolumn{2}{|c|}{6,03} \\
\hline
\end{tabular}

$\mathrm{CA}=$ Carga alta $* * \mathrm{CI}=$ Carga intermediária. Médias seguidas de mesmas letras nas linhas, comparadas entre as duas cargas para cada variável isolada: café caído, café remanescente e eficiência de colheita, não diferem entre si, pelo teste t a 5\% de probabilidade. 
Com três ou mais operações da colhedora, o volume remanescente de frutos nas plantas não justifica ou pode dispensar o repasse manual na lavoura de carga alta $\left(121,54\right.$ sacas de café ben ha $\left.{ }^{-1}\right)$. $\mathrm{Na}$ lavoura com carga intermediaria $(50,78$ sacas de café ben ha $\left.^{-1}\right)$, duas operações são suficientes.

Independentemente da carga de café, a colheita mecanizada com três operações da colhedora colhe mais café, no entanto, sem haver diferença quanto a eficiência de colheita na lavoura de carga intermediária $\left(50,78\right.$ sacas de café ben ha $\left.^{-1}\right)$ e apresenta maior eficiência de colheita.

\section{REFERÊNCIAS}

CASSIA, M.T. et al. Quality of mechanized coffee harvesting in circular planting system. Ciência Rural, v.43, n.1, p.2834, 2013. Disponível em: <http://dx.doi.org/10.1590/S010384782012005000148>. Acesso em: 15 abr. 2015. doi: 10.1590/ S0103-84782012005000148.

COMPANHIA NACIONAL DE ABASTECIMENTO. Indicadores agropecuários. Disponível em: $<$ http://www.conab. gov.br>. Acesso em: 10 mar. 2014.

FERNANDES, A.L.T. et al. A moderna cafeicultura dos cerrados brasileiros. Pesquisa Agropecuária Tropical, v.42, n.2, p.23140, 2012. Disponível em: <http://dx.doi.org/10.1590/S198340632012000200015>. Acesso em: 15 abr. 2015. doi: 10.1590/ S1983-40632012000200015.

FERREIRA, D.F. Sisvar: a computer statistical analysis system. Ciência e Agrotecnologia, v.35, n.6, p.1039-1042, 2011. Disponível em: <http://dx.doi.org/10.1590/S141370542011000600001>. Acesso em: 15 abr. 2015. doi: 10.1590/ S1413-70542011000600001.

KÖEPPEN, W. Climatologia: con um estúdio de los climas de la Tierra. México: Fondo de Cultura Economica, 1948. 478p.
LANNA, G.B.M.; REIS, P.R. Influência da mecanização da colheita na viabilidade econonômico-financeira da cafeicultura no sul de Minas Gerais. Coffee Science, v.7, n.2, p.110-121, 2012. Disponível em: <http://www.coffeescience.ufla.br/index.php/ Coffeescience/article/view/194/pdf>. Acesso em: 15 abr. 2015.

OLIVEIRA, E. et al. Influência da vibração das hastes e da velocidade de deslocamento da colhedora no processo de colheita mecanizada do café. Engenharia Agrícola, v.27, n.3, p.71421, 2007a. Disponível em: <http://dx.doi.org/10.1590/S010069162007000400014>. Acesso em: 15 abr. 2015. doi: 10.1590/ S0100-69162007000400014.

OLIVEIRA, E. et al. Influência da colheita mecanizada na produção cafeeira. Ciência Rural, v.37, n.5, p.1466-1470, 2007 b. Disponível em: <http://www.scielo.br/pdf/cr/v37n5/a41v37n5. pdf>. Acesso em: 15 abr. 2015.

REIS, T.H.P. et al. Informações úteis no planejamento e no gerenciamento da atividade cafeeira. Informe Agropecuário, v.29, n.247, p.112-27, 2008.

SANTINATO, F. et al. Análise quali-quantitativa da operação de colheita mecanizada de café em duas safras. Coffee Science, v.9, n.4, p.495-505, 2014. Disponível em: <http://www.coffeescience. ufla.br/index.php/Coffeescience/article/view/737/pdf_131>. Acesso em: 15 abr. 2015.

SILVA, F.C. et al. Comportamento da força de desprendimento dos frutos de cafeeiros ao longo do período de colheita. Ciência e Agrotecnologia, v.34, n.2, p.468-474, 2010. Disponível em: $<$ http://dx.doi.org/10.1590/S1413-70542010000200028>. Acesso em: 15 abr. 2015. doi: 10.1590/S1413-70542010000200028.

SILVA, F.C. et al. Desempenho operacional da colheita mecanizada e seletiva do café em função da força de desprendimento dos frutos. Coffee Science, v.8, n.1, p.53-60, 2013. Disponível em: $<$ http://www.coffeescience.ufla.br/index.php/Coffeescience/ article/view/345/pdf>. Acesso em: 15 abr. 2015.

SILVA, F.M et al. Avaliação da colheita do café totalmente mecanizada. Engenharia Agrícola, v.23, n.2, p.309-315, 2003. 